\title{
Long-Term Neuroprotective Effect of Postischemic Hypothermia in a Neonatal Rat Model of Severe Hypoxic Ischemic Encephalopathy: A Comparative Study on the Duration and Depth of Hypothermia
}

\author{
BYONG SOP LEE, CHUL-WOONG WOO, SANG-TAE KIM, AND KI-SOO KIM \\ Department of Pediatrics [B.S.L., K.-I.K.], Asan Medical Center, University of Ulsan College of Medicine, Seoul 138-736, Korea; NMR \\ Laboratory [C.-W.W., S.-T.K., K.-S.K.], Asan Institute for Life Sciences, Seoul 138-736, Korea
}

\begin{abstract}
It is not known whether deeper or longer hypothermia (HT) can achieve better neuroprotection against hypoxic ischemic encephalopathy (HIE) in neonates. To compare the neuroprotective effects of different durations and temperatures of postischemic HT in neonatal rats with severe HIE, 7-d-old rats were subjected to the Rice-Vannucci model for $150 \mathrm{~min}$ hypoxia. Only the rats with identified brain lesions in diffusion-weighted MRI were assigned to normothermia $\left(\mathrm{NT}, 36^{\circ} \mathrm{C} / 48 \mathrm{~h}\right.$ ) or four HT (HT-30 ${ }^{\circ} \mathrm{C} / 48 \mathrm{~h}$; HT$30^{\circ} \mathrm{C} / 24 \mathrm{~h}$; HT- $33^{\circ} \mathrm{C} / 48 \mathrm{~h}$; and $\mathrm{HT}-33^{\circ} \mathrm{C} / 24 \mathrm{~h}$ ) groups. ${ }^{1} \mathrm{H}$-magnetic resonance spectroscopy $\left({ }^{1} \mathrm{H}-\mathrm{MRS}\right)$ and T2-weighted MRI were obtained serially, and functional studies were performed. HT groups showed significantly greater residual hemispheric volume and better rotarod and cylinder tests than did the NT group at $5 \mathrm{wk}$ postischemia. HT groups also showed lower lactate-plus-lipid level in ${ }^{1} \mathrm{H}$ MRS than did the NT group at $7 \mathrm{~d}$ postischemia. All of these outcome variables, however, did not differ among the 4 HT subgroups, despite a trend toward greater residual brain volume in the 48-h HT versus 24-h HT subgroups. In conclusion, neither reducing the target temperature from 33 to $30^{\circ} \mathrm{C}$ nor prolonging the duration from 24 to $48 \mathrm{~h}$ produced further improvements in neurologic outcomes in neonatal rat with HIE. (Pediatr Res 68: 303-308, 2010)
\end{abstract}

$\mathrm{H}$ ypothermia (HT) is one of the most promising neuroprotective modalities against hypoxic ischemic encephalopathy (HIE) in neonatal brain (1). However, in neonates with severe HIE, little neuroprotection could be achieved using current HT protocols in which whole-body or head cooling is performed for 48 to $72 \mathrm{~h}$ by maintaining the core temperature within a range of 33.5 to $34.5^{\circ} \mathrm{C}(2-5)$. In animal studies, the efficacy of postischemic HT was also limited in the subgroup with severe ischemic injury $(6,7)$. To treat severe HIE by HT, a recent review suggested a "deeper" and "more prolonged" cooling (8). However, no controlled clinical trials have tested this supposition and several experimental studies failed to clearly demonstrate an effect of postischemic HT protocols with different target temperatures or duration in a perinatal HIE model (9-11).

Received March 8, 2010; accepted June 18, 2010

Correspondence: Ki-Soo Kim, M.D., Ph.D., Department of Pediatrics, University of Ulsan College of Medicine, Asan Medical Center, 388-1, Poongnap-dong, Songpa-gu, Seoul 138-736, South Korea; e-mail: kskim@amc.seoul.kr

Supported by a Grant (2008-10465) from the Asan Institute for Life Sciences, Seoul, Korea.
The 7-d-old rat with unilateral carotid artery ligation and subsequent exposure to $8 \%$ hypoxia is the most commonly used model to evaluate the efficacy of therapeutic interventions in the developing brain (12), and several studies have used this Rice-Vannucci model (RVM) to test the effects of HT (10,11,13-19). However, an experimental design composed of a shorter duration of hypoxia, representing "mild" ischemic lesions, is not appropriate for evaluating the neuroprotective effect of HT against severe HIE. To date, few experimental studies have used the RVM with hypoxia exposure longer than 120 min $(10,13,19)$, but none of these have reported the long-term neuroprotective effect of postischemic HT.

The aim of this study was to investigate the long-term neuroprotective effect of various postischemic HT protocols with different target temperatures and duration in a neonatal rat model of severe HIE.

\section{METHODS}

Animal model of HIE. Animal experiments were performed in accordance with the National Institutes of Health guidelines for humane handling of animals and were approved by the Committee of Animal Research of Asan Medical Center. Surgical procedures were performed on postnatal day 7 male Sprague-Dawley rats $(n=130,10$ litters). Rats were subjected to a wellcharacterized RVM (12). Briefly, rat pups were anesthetized with isoflurane gas (induction, $4.0 \%$; maintenance, $1.0 \%$ ) in oxygen:nitrous oxide (1:1). The right common carotid artery was ligated using 5/0 silk following midline incision. After $1 \mathrm{~h}$ recovery period, the pups were placed in a chamber maintained at a temperature of $36^{\circ} \mathrm{C}$ and exposed to humidified $8 \%$ oxygen for $150 \mathrm{~min}$. After 15-min recovery period, diffusion weighted images (DWIs) and ${ }^{1} \mathrm{H}$-magnetic resonance spectroscopy (MRS) were obtained. The time for the initial imaging study was about 15 min for each pup (total time for one experimental set $<3.5 \mathrm{~h}$ ). Only those rats with identified unilateral brain lesions in DWIs were assigned to the study groups of temperature intervention and the final studies of outcome measurement. Rats without apparent brain lesions or with severe lesions extending to the contralateral hemisphere were not included in the study and returned to their mothers until euthanized. After anesthesia, sham animals underwent exposure of the common carotid artery without ligation. During the intervention period, these rats, like the animals in the NT groups, were separated from their mothers and intermittently gavage-fed.

Abbreviations: DWI, diffusion-weighted image; HIE, hypoxic ischemic encephalophaty; HT, hypothermia; MRS, magnetic resonance spectroscopy; NAA, $N$-acetyl aspartate; NT, normothermia; RVM, Rice-Vannucci model; T2WI, T2-weighted image 
Postischemic temperature modulation. Rats were classified into a sham group, a normothermia (NT) group $\left(36^{\circ} \mathrm{C} / 48 \mathrm{~h}\right)$ and four HT groups: HT$33 / 24 \mathrm{~h}\left(33^{\circ} \mathrm{C} / 24 \mathrm{~h}\right), \mathrm{HT}-30 / 24 \mathrm{~h}\left(30^{\circ} \mathrm{C} / 24 \mathrm{~h}\right), \mathrm{HT}-33 / 48 \mathrm{~h}\left(33^{\circ} \mathrm{C} / 48 \mathrm{~h}\right)$, and HT-30/48 h $\left(30^{\circ} \mathrm{C} / 48 \mathrm{~h}\right)$. For temperature intervention, pups were separated from their mothers and placed in a temperature-controlled chamber within which each pup was separated from the others by an acryl lattice to prevent temperature elevation through gathering. For groups of HT-30 and HT-33, temperature inside the chamber was initially set at 27.0 and $31.0^{\circ} \mathrm{C}$, respectively, with minimal adjustment throughout the intervention period. By using a flexible temperature probe, rectal temperature was measured at 1 and $4 \mathrm{~h}$, and thereafter every $4 \mathrm{~h}$ until the end of each intervention period. Through the period of temperature intervention, pups were fed five times per day with 0.4 $\mathrm{mL}$ of commercially available ready-to-feed formula by using $22 \mathrm{G}$-animal feeding needle with round (15). After temperature intervention, the pups were returned to their dams until the end of imaging studies and functional studies at $5 \mathrm{wk}$ postinsult.

MRI and ${ }^{\boldsymbol{1}} \boldsymbol{H}$-MRS. Animals were maintained under anesthesia with $1 \%$ isoflurane in a 1:2 mixture of $\mathrm{O}_{2}: \mathrm{N}_{2} \mathrm{O}$. Images and MRS data were obtained using a 4.7-T MRI/MRS system (Bruker BioSpin, Karlsruhe, Germany) with a custom-made $25-\mathrm{mm}$ diameter animal microimaging coil. Axial slices corresponding to coronal images in the neuroanatomic axis were collected from the cervical spinal cord to the olfactory bulb. MRIs and ${ }^{1} \mathrm{H}-\mathrm{MRS}$ images were obtained at assigned times as follows: 1) immediately after injury(d 0), DWI $/{ }^{1} \mathrm{H}-\mathrm{MRS}$; 2) $2 \mathrm{~d}$ after injury (d 2), T2-weighted images (T2WI)/ ${ }^{1} \mathrm{H}$ MRS; 3) $7 \mathrm{~d}$ after injury(d 7), T2WI $/{ }^{1} \mathrm{H}-\mathrm{MRS}$; and 4) $35 \mathrm{~d}$ after injury(d 35), T2WI. Images at d 2 were obtained after completion of temperature intervention. The imaging protocol included a DWI $[\mathrm{TR}=2000 \mathrm{~ms}$; TE $=76 \mathrm{~ms}$; slice thickness $=1.5 \mathrm{~mm}$; matrix $=128 \times 64$; field of view $=20 \times 20 \mathrm{~mm}$; and diffusion $B$ value $=2217.7 \mathrm{~s} / \mathrm{mm}^{2}$ (no gap)], and a T2WI [TR $=4500 \mathrm{~ms}$; $\mathrm{TE}=80 \mathrm{~ms}$; slice thickness $=1.5 \mathrm{~mm}$; and matrix $=256 \times 256$ (no gap)] The spectra from ${ }^{1} \mathrm{H}$-MRS were acquired through a signal voxel $(3 \times 3 \times 3$ $\mathrm{mm}^{3}$ ) in the right parietotemporal region using a spin-acquisition mode sequence for 128 acquisitions with a TR of $3000 \mathrm{~ms}$ and a TE of $30 \mathrm{~ms}$. All raw spectroscopic data were processed using the XWIN-NMR software provided with the scanner. The integrated area of the following metabolite peaks was recorded: $N$-acetyl aspartate (NAA) at $2.0 \mathrm{ppm}$; lactate-plus-lipid at $1.3 \mathrm{ppm}$; and lipid at $0.9 \mathrm{ppm}$. The relative sizes of the peak areas for each metabolite were quantified based on creatine levels at $3.0 \mathrm{ppm}$ by an examiner blind to the study group.

Measurement of extent of brain injury. Volumetric analyses of MR images were performed using ParaVision 2.0.2 (Bruker, BioSpin, Karlsruhe, Germany). The boundary of each lesion was identified by a well-demarcated hyperintense area in T2WI at d 7 and $d 35$. To compensate for the effect of brain edema or shrinkage, the percent of the "intact" volume of the affected ipsilateral relative to the unaffected contralateral hemisphere was used as the outcome parameter; in each coronal image, the intact area of the ipsilateral hemisphere (i.e. the hemispheric area excluding the regions of hyper-intensity representing infarct or liquefaction) was outlined manually by two examiners blinded to group assignment. The size of the selected area was calculated automatically using the same software program. The residual brain volume of the ipsilateral hemisphere was calculated by summing the values of the intact area from six consecutive 1.5 -mm-thick axial slices obtained caudally from the bregma level. Each of the six slices corresponded to coronal plate numbers $17,24,31,38,44$, and 49 in the adult rat brain atlas of Paxinos (20). The volume of the contralateral hemisphere was calculated in the same manner. The percent of residual brain volume was calculated as (ipsilateral residual hemispheric volume/intact contralateral hemisphere volume) $\times 100$. The values calculated by the two examiners was averaged and used in the final data analysis. Because the margin of the brain edema in MRIs obtained at $d$ 0 and d 2 was blurred, we could not calculate the volume of brain edema. Instead, the extent of brain edema in DWIs at d 0 was categorized roughly into moderate (confined to the cortex, but without apparent lesions in the striatum or hippocampus) or severe (extension beyond the cortex into the striatum, thalamus, or hippocampus) injury by an examiner blinded to the study outcome (21).

Functional studies. Two functional tests were performed to evaluate sensorimotor function at $\mathrm{d} 37$ by an examiner blind to the study group.

The length of time that a rat remained on the rotarod treadmill was measured (latency to fall). The rotation speed was accelerated from 4 to 40 rpm over $100 \mathrm{~s}$ for a maximum of $5 \mathrm{~min}$. The average latency to fall from three trials, with a 15-min intertrial interval, was used as the measured parameter.

Asymmetry of forelimb use was determined by analyzing the movements of each rat during exploratory activity within a transparent polyacrylate cylinder $(20 \mathrm{~cm}$ in diameter and $34 \mathrm{~cm}$ in height) with two mirrors positioned behind the cylinder. The forepaw placement of each weight-bearing contact with the wall during a full rear was recorded; "bilateral" was recorded in cases of simultaneous contact with both forepaws. Each animal was video-recorded for $4 \mathrm{~min}$ in each session. Data are presented as the scores of limb-use asymmetry according to the following formula: [number of (left contacts + $1 / 2$ of bilateral contacts $) /$ number of (left + right + bilateral contacts $)] \times 100$. This resulted in an asymmetry score that was lower for animals with poorer performance, i.e. decreased use of the affected (left) limb. All animals were recorded three times, and the average score of the trial(s) was recorded. For each animal, "inactive" trials (i.e. $<12$ wall movements per session) were excluded from the calculation of average scores.

Statistical analysis. $\chi^{2}$ tests or Kruskal-Wallis tests were used to compare the mortality between the groups. $t$ test was used in the quantitative analysis of the percent of residual volume and functional tests between two groups. The interobserver variability for percent of residual volume was assessed using Pearson's correlation coefficient. An ANOVA with Tukey's HSD test was used to compare the parameters among the four subgroups of HT. A repeated-measures ANOVA was used to compare ${ }^{1} \mathrm{H}-\mathrm{MRS}$ values at $\mathrm{d} 0, \mathrm{~d} 2$, and $\mathrm{d} 7$, with each parameter (e.g. NAA) as a within-subject factor and study groups as the between-subject factor. The effects of the severity of initial brain injury and HT on final residual brain volume were assessed by two-way ANOVA. All statistical analyses were performed with SPSS 13.0 for Windows.

\section{RESULTS}

Survival rates and final weights. A total of 102 pups with identified brain lesions in d 0 DWIs were included in the study. The mortality rate did not differ between the HT (7/68) and the NT (5/34) groups during the course of the study period. Mortality among HT groups also did not differ: HT33/24 h (1/17), HT-30/24 h (2/17), HT-33/48 h (0/16), and HT-30/48 h (4/18) $(p=0.171)$. Mean body weight at d $35 \mathrm{did}$ not differ between the NT $(182.5 \pm 14.5 \mathrm{~g})$ and the HT $(179.3 \pm 18.3 \mathrm{~g})$ groups.

Maintenance of rectal temperature. Before temperature intervention, rectal temperature did not differ between the NT $\left(35.8 \pm 1.2^{\circ} \mathrm{C}\right)$ and the HT $\left(35.6 \pm 1.0^{\circ} \mathrm{C}\right)$ groups. From $1 \mathrm{~h}$ after initiating temperature control, rectal temperature within each group remained stable during the intervention period ( 24 or 48 h; Fig. 1).

Long-term neurologic outcomes. HT groups showed better outcomes than the NT group in the percent of residual volume at d 35 (sham, $98.8 \pm 5.4 \%$; NT, $42.2 \pm 20.5 \%$; and HT, $57.1 \pm 21.4 \%$ ), the rotarod test (sham, $176.7 \pm 53.9 \mathrm{~s}$; NT, $64.7 \pm 37.0 \mathrm{~s}$; and HT, $96.5 \pm 50.4 \mathrm{~s})$, and the cylinder test (sham, $48.3 \pm 3.5 \%$; NT, $31.4 \pm 11.1 \%$; and HT, $36.9 \pm$ $10.1 \%$ ) (Fig. 2). The concordance between both readers in determining the percent of residual volume at $\mathrm{d} 35$ showed an excellent correlation coefficient $\left(R_{\mathrm{p}}=0.943, p<0.001\right)$. A

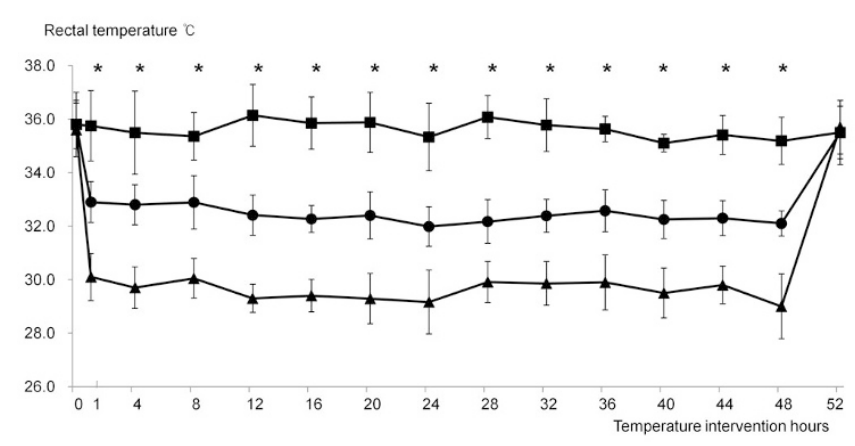

Figure 1. Measurement of rectal temperature in the NT (ם) group and two representative HT subgroups (HT-30/48 h ( ) and HT-33/48 h ( $\mathbf{\Delta})$. Temperatures within each group remained stable during the intervention period and were significantly different among groups at each time point of measurement $(* p<0.001$ by ANOVA). 
A Residual hemispheric volume

(\%)

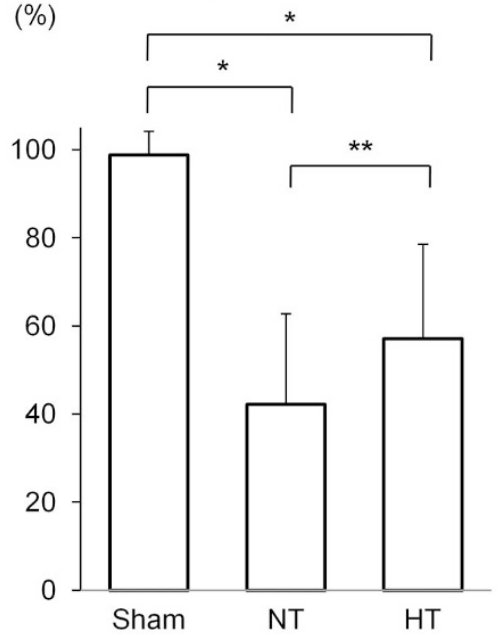

B Latency to fall (s)

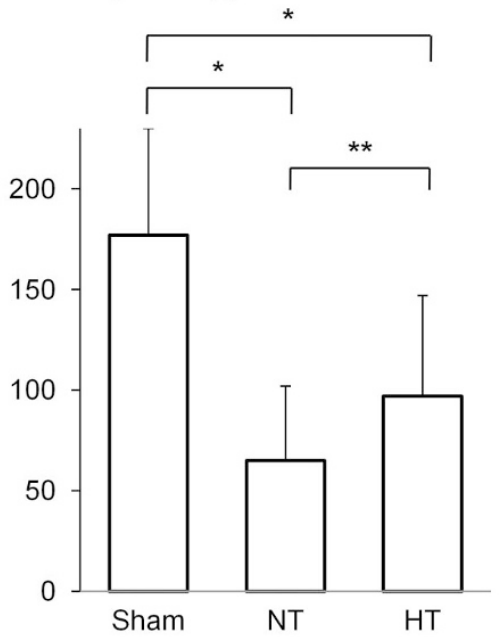

C Limb-use asymmetry (\%)
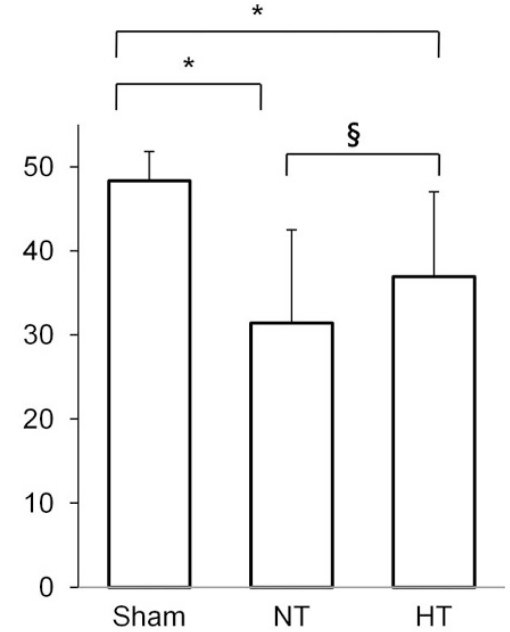

Figure 2. Long-term neurologic outcomes in each study group. A, Percent of residual ipsilateral to contralateral hemispheric volume at $\mathrm{d} 35 ; B$, rotarod test; $C$, cylinder test $(* p<0.001, * * p<0.01, \S p<0.05$ by $t$ test $)$.
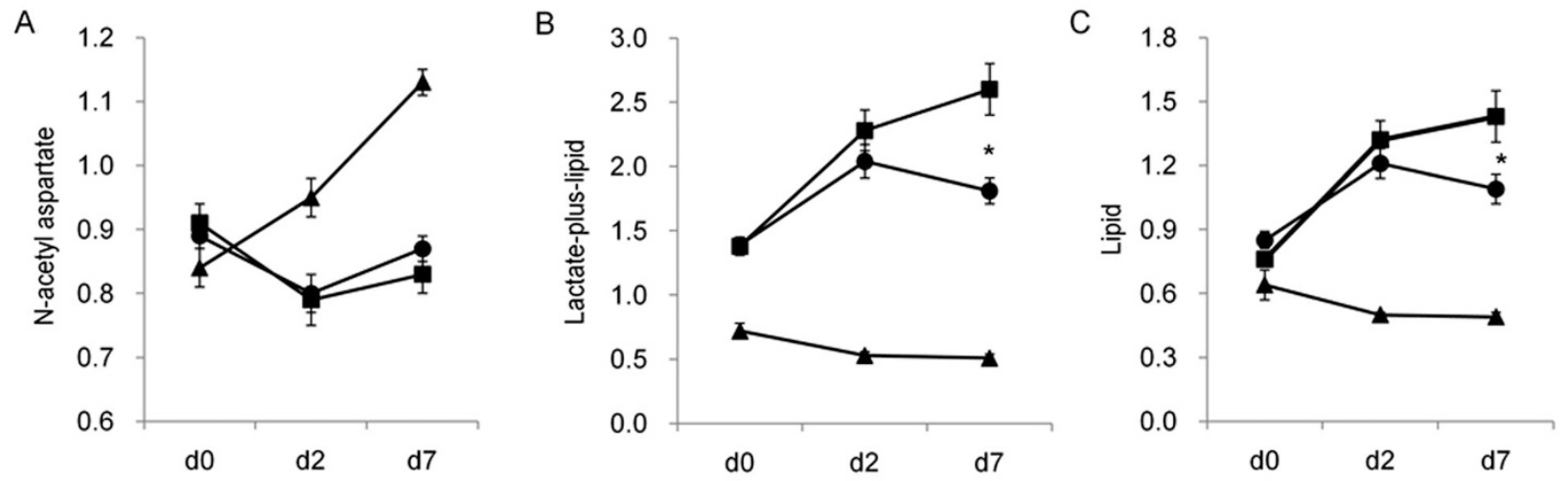

Figure 3. Serial changes in ${ }^{1} \mathrm{H}-\mathrm{MRS}$ data in the study groups. $A, N$-acetyl aspartate; $B$, lactate-plus-lipid; $C$, lipid $\left({ }^{*} p<0.05\right.$ for HT $v s$. NT group). Mean ( \pm SEM) values (with error bars) for each parameter in sham $(\boldsymbol{\Delta})$, NT (ם), and HT (๑) $\left({ }^{*} p<0.05\right.$ for HT $v s$. NT group).

comparative analysis showed an excellent correlation between residual hemispheric volume at $\mathrm{d} 7$ and d $35\left(R_{\mathrm{p}}=0.922, p<\right.$ $0.001)$. The residual hemispheric volume ratio at $\mathrm{d} 35$ was significantly correlated with the results of rotarod test $\left(R_{\mathrm{p}}=\right.$ $0.333, p<0.001)$ and cylinder test $\left(R_{\mathrm{p}}=0.386, p<0.001\right)$.

${ }^{1} \boldsymbol{H}$-MRS study. At d 0, while the levels of NAA did not differ among the sham $(0.84 \pm 0.12)$, the NT $(0.91 \pm 0.15)$, and the HT $(0.89 \pm 0.17)$ groups, the level of lactate-pluslipid was significantly higher in the NT $(1.38 \pm 0.38)$ and the HT $(1.39 \pm 0.40)$ groups compared with the sham $(0.72 \pm$ 0.24) group. After temperature intervention, both NT and HT groups showed lower levels of NAA and higher levels of lactate-plus-lipid and lipid than the sham group at each time point (Fig. 3). Repeated-measures ANOVAs between the NT and the HT groups revealed a significant change in lactateplus-lipid $(p<0.01)$ and lipid $(p<0.001)$ levels at each time of measurement after hypoxic injury. NAA levels did not change significantly over the course of the experiment. HT was effective in reducing the increased level of lactate-pluslipid after HIE $(p<0.05)$. At $\mathrm{d} 7$, the level of lactate-pluslipid in the HT group $(1.50 \pm 0.83)$ was significantly lower than that in the NT group $(2.02 \pm 1.11)$; lipid levels were also lower in the HT group $(1.09 \pm 0.52)$ than in the NT group $(1.43 \pm 0.69)$. NAA levels did not differ between the NT $(0.83 \pm 0.19)$ and HT $(0.87 \pm 0.17)$ groups.

Effect of depth and duration of HT on neurologic outcome. Subgroup analyses between the two subgroups with different target temperature but the same HT duration or between the two subgroups with different duration but the same target temperature revealed no differences in the residual hemispheric volume or functional studies at 5 wk postinsult (Table 1). Although residual brain volume $(60.5 \pm 22.3 \%$ versus $53.8 \pm 20.3 \%)$ and cylinder test $(38.9 \pm 11.1 \%$ versus $34.9 \pm 8.7 \%$ ) results trended higher in the two $48 \mathrm{~h}$-HT subgroups compared with the two $24 \mathrm{~h}-\mathrm{HT}$ subgroups, these differences did not reach statistical significance.

Subgroup analyses of ${ }^{1} \mathrm{H}$-MRS results between groups with different duration but the same target temperatures revealed a greater level of NAA in the subgroups treated with $48 \mathrm{~h}$ of HT at both $33^{\circ} \mathrm{C}(p<0.001)$ and $30^{\circ} \mathrm{C}(p<0.05)$ at $\mathrm{d} 2$. Accordingly, as expected, the level of NAA was greater in the 48-h HT subgroups $(0.90 \pm 0.18)$ than in the 24-h HT 
Table 1. Comparison of neurologic outcomes in the four HT subgroups

\begin{tabular}{|c|c|c|c|c|c|}
\hline Parameters & $33 / 24 \mathrm{~h}(n=16)$ & $30 / 24 \mathrm{~h}(n=15)$ & $33 / 48$ h $(n=16)$ & $30 / 48$ h $(n=14)$ & $p$ \\
\hline Residual brain volume $(\%)^{*}$ & $52.4 \pm 21.7$ & $55.4 \pm 19.3$ & $61.4 \pm 20.1$ & $59.4 \pm 25.4$ & NS \\
\hline Rotarod test (s) & $87.1 \pm 44.6$ & $109.9 \pm 68.2$ & $106.7 \pm 50.3$ & $81.1 \pm 28.4$ & NS \\
\hline Cylinder test (\%) & $35.1 \pm 10.4$ & $34.6 \pm 7.1$ & $37.0 \pm 10.6$ & $40.9 \pm 11.7$ & NS \\
\hline \multicolumn{6}{|l|}{$N$-acetyl aspartate } \\
\hline $\mathrm{d} 0$ & $0.84 \pm 0.18$ & $0.87 \pm 0.19$ & $0.94 \pm 0.14$ & $0.92 \pm 0.14$ & NS \\
\hline d 2 & $0.68 \pm 0.18$ & $0.73 \pm 0.20$ & $0.95 \pm 0.21$ & $0.86 \pm 0.13$ & NS \\
\hline d 7 & $0.85 \pm 0.18$ & $0.82 \pm 0.14$ & $0.92 \pm 0.18$ & $0.91 \pm 0.15$ & NS \\
\hline \multicolumn{6}{|l|}{ Lactate-plus-lipid } \\
\hline $\mathrm{d} 0$ & $1.20 \pm 0.45$ & $1.52 \pm 0.38$ & $1.36 \pm 0.30$ & $1.51 \pm 0.38$ & NS \\
\hline $\mathrm{d} 2$ & $2.31 \pm 1.14$ & $1.82 \pm 0.75$ & $2.08 \pm 1.12$ & $1.96 \pm 1.11$ & NS \\
\hline d 7 & $1.50 \pm 0.86$ & $1.60 \pm 0.85$ & $1.33 \pm 0.57$ & $1.58 \pm 1.02$ & NS \\
\hline \multicolumn{6}{|l|}{ Lipid } \\
\hline d 0 & $0.69 \pm 0.20$ & $0.97 \pm 0.32$ & $0.86 \pm 0.26$ & $0.90 \pm 0.32$ & NS \\
\hline d 2 & $1.21 \pm 0.41$ & $1.12 \pm 0.47$ & $1.27 \pm 0.67$ & $1.23 \pm 0.73$ & NS \\
\hline d 7 & $1.06 \pm 0.44$ & $1.26 \pm 0.58$ & $0.95 \pm 0.39$ & $1.12 \pm 0.64$ & NS \\
\hline
\end{tabular}

Data are presented as means \pm SDs among the four HT subgroups, by ANOVA.

* Percent of ipsilateral intact hemispheric volume to contralateral hemispheric volume.

NS, not significant.

subgroups $(0.70 \pm 0.19)$ at $\mathrm{d} 2(p<0.001)$. Subgroup analyses performed as described earlier showed that neither lactate-plus-lipid nor lipid levels differed among subgroups at any measurement time.

Effect of severity of ischemic injury on neurologic outcome. On the basis of the results of the extent of the brain edema in DWIs at $\mathrm{d} 0$, we categorized rats into moderate $(n=$ $52)$ or severe $(n=50)$ initial injury groups. The ratio of rats with initial severe ischemic injury did not differ among groups: NT (19/34); HT-33/24 h (8/17); HT-30/24 h (8/17); HT-33/24 h (7/16); and HT-33/48 h (8/18). Two-way ANOVAs demonstrated that both the severity of ischemic injury and HT influenced several markers for long-term neurologic outcomes in neonatal rats with HIE, although not all changes were statistically significant (Figs. 4 and 5).

\section{DISCUSSION}

Postischemic HT with a duration of $24 \mathrm{~h}$ or longer and/or a target temperature of $33^{\circ} \mathrm{C}$ or lower, started within $3.5 \mathrm{~h}$ after recovery, decreased infarct volume and improved sensorimotor functions in a neonatal rat model of severe HIE. This long-term neuroprotective effect of postischemic HT was previously demonstrated in several studies using neonatal rats $(6,11,14-17)$. However, ours is the first study to investigate the effect of both duration and depth of HT in a neonatal rat HIE model.

Lowering the target rectal temperature from 33 to $30^{\circ} \mathrm{C}$ did not provide additional neuroprotection against severe HIE in the neonatal rat. This is in accord with the results of a few animal studies that focused on the effect of different HT target temperatures, although the temperature range varied among the studies $(10,18-19,22)$. Interestingly, another piglet study demonstrated a different HT temperature threshold between brain regions; whereas $\mathrm{HT}$ at $35^{\circ} \mathrm{C}$ and $33^{\circ} \mathrm{C}$ achieved better neuroprotection in the deep gray matter and in the cortical gray matter, respectively, (9). Whether this differential neuroprotection afforded by different HT target temperatures also applies to the smaller brain of the neonatal rat is uncertain.



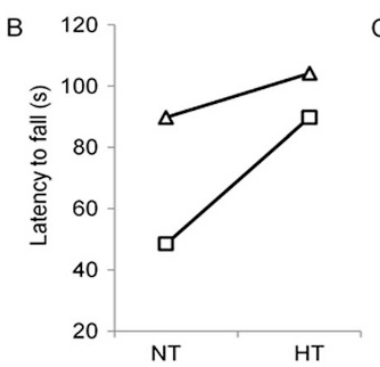
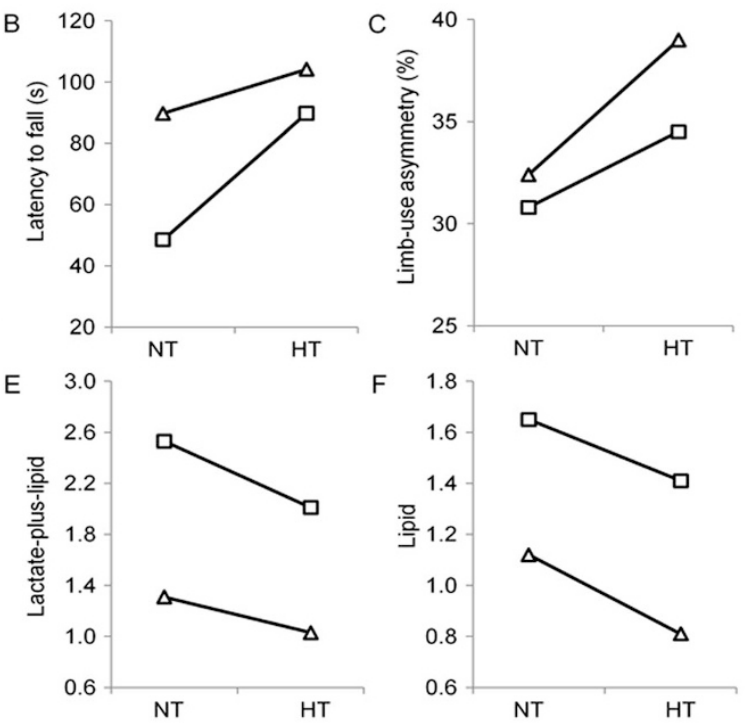

Figure 4. Two-way ANOVA demonstrating the dual effects of severity of initial ischemic damage (SI) and HT therapy on long-term neurologic outcomes. Mean values for moderate $(\triangle)$ and severe $(\square)$ initial damage groups. The severity of initial damage was based on the DWI at d 0 (see text). $A$, Percent of residual brain volume ( $p<0.001$ for SI; $p=0.001$ for HT); $B$, rotarod test $(p<0.01$ for SI; $p<0.05$ for $\mathrm{HT}$ ); $C$, cylinder test (not significant for SI; $p<0.05$ for HT); $D, N$-acetyl aspartate at d 7 (not significant for SI or HT); $E$, lactate-plus-lipid at d 7 ( $p<0.001$ for SI; $p<0.05$ for HT); and $F$, lipid at $\mathrm{d} 7$ ( $p<0.001$ for SI; $p<0.05$ for HT). 


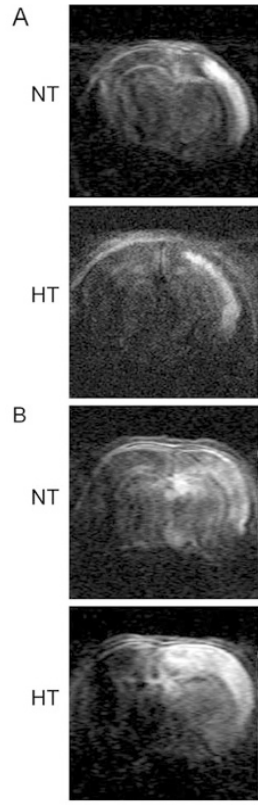

d0

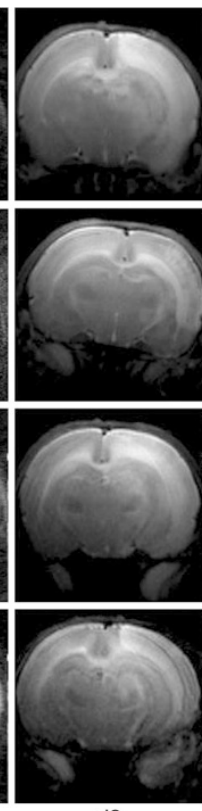

d2

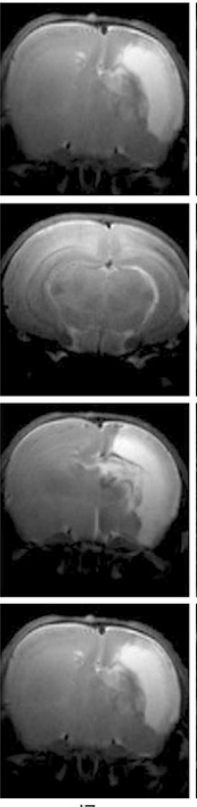

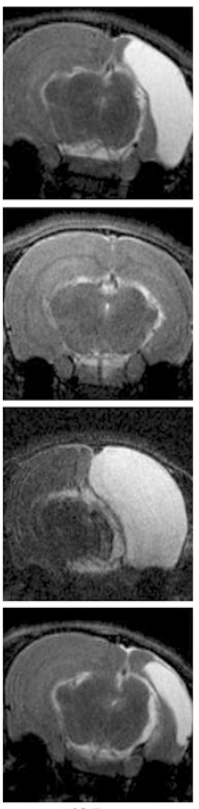

d35
Figure 5. Evolution of brain lesions, as assessed by diffusion weighted (d 0 ) or T2-weighted (d 2, d 7, and d 35) MRIs in representative 7-d-old rat pups after right common carotid artery ligation and exposure to $8 \%$ oxygen for 150 min. Rats were categorized as having initially moderate $(A)$ or severe $(B)$ injury based on DWI findings obtained immediately after ischemic-insult and were treated with NT (first row) or HT (second row) for $48 \mathrm{~h}$.

The subgroups treated with 48 h-HT did not clearly demonstrate better long-term neurologic outcomes than the subgroups with $24 \mathrm{~h}-\mathrm{HT}$. Although studies in adult animals have shown a beneficial effect of prolonged HT, the duration was markedly shorter than in current practice $(23,24)$. Strategies that extend the period of HT beyond the therapeutic window generally target cells undergoing delayed neuronal death. In animal models of HIE, the phenotype of cell death varies depending on brain maturity, time, and the severity of the insult $(25,26)$. Although necrosis is a major form of early neuronal death after HIE, both in neonatal and adult models, apoptosis plays a significant role in the delayed neuronal death that occurs $24 \mathrm{~h}$ after ischemic insult, especially in the developing brain (26-28). However, in RVM exposed to $2 \mathrm{~h}$ of hypoxia, the major pattern of neuronal death is still necrosis in most regions, particularly for the first $48 \mathrm{~h}$ postischemia (26). Moreover, the long-term contribution of delayed neuronal death to the final infarct volume is less significant than in rats exposed to $75 \mathrm{~min}$ of hypoxia (29). Delayed death of neurons remote from the ischemic core or from the penumbra (e.g. thalamus) has been found to be secondary to the loss of trophic support from the area of primary insult (29). Thus, in the case of a severe ischemic infarct in RVM, postischemic HT starting $24 \mathrm{~h}$ after the insult may have a lower probability of rescuing the neurons, not only in the ischemic core and penumbra but also in the deep brain regions, where death is due to target deprivation-mediated injury.

We also observed a trend toward increased residual brain volume and cylinder test results, as well as significant NAA preservation, after $48 \mathrm{~h}$ of HT. To extrapolate our results to clinical trials, it is important to consider differences between neonatal rats and newborn infants in their stage of brain maturation, brain size, mode of ischemic insult, and cell death phenotypes. Unfortunately, we did not investigate whether further extension of HT duration to $72 \mathrm{~h}$, the period of HT in clinical settings, results in better neuroprotection compared with shorter HT duration. There have been few animal studies of $72 \mathrm{~h}$-HT $(30,31)$ and none of these has systematically addressed issues regarding the duration of HT.

Contrary to ${ }^{1} \mathrm{H}$-MRS profiles after HT in a piglet model of HIE (32), we found that signal levels at $1.3 \mathrm{ppm}$, representing lactate-plus-lipid, did not differ between the NT and HT groups at $2 \mathrm{~d}$ postinsult. Only at $\mathrm{d} 7$, during the chronic phase of ischemic injury, the levels were lower in the HT than the NT groups. The persistently elevated signal at $1.3 \mathrm{ppm}$ beyond 24 to $48 \mathrm{~h}$ postischemia was probably not due to the anaerobic production of lactate, but rather to lactate production by infiltrating phagocytic cells (33) or a signal overlap between lactate and lipids $(34,35)$. These signals arise from neutral lipid droplets localized to the microglia/macrophages in the infarct area (36). The difference in the $\mathrm{d} 7$ signal peak between the NT and HT groups at both 1.3 and $0.9 \mathrm{ppm}$ likely represents the difference in the extent of brain infarct.

By roughly dichotomizing the severity of brain injury with DWIs, we demonstrated a neuroprotective effect of HT in neonatal rats with different degrees of HIE. Even in the subgroups with marked ischemic injury, HT showed longterm neuroprotection. This tool to identify and measure the extent of brain injury without sacrificing the subjects is valuable in designing studies to compare the efficacy of a given therapeutic intervention because even after the same period of hypoxic-exposure in the RVM, wide individual variations can exist in the extent of brain damage (25). The extent of lesions appeared in MRIs immediately after the insult well reflect the pathologic stage of the acute ischemic injury and also correlates well with the long-term histologic outcome $(6,37)$. Unfortunately, poor resolution of DWIs obtained with shorter acquisition times failed to provide a quantitative measurement of the extent of the initial ischemic injury.

In conclusion, although postischemic HT decreased the extent of brain infarct and improved functional outcomes in 7-d-old rats with severe HIE, the benefit of longer or deeper HT was still not conclusive. However, the trend toward better neuroprotection of $48 \mathrm{~h}-\mathrm{HT}$ versus $24 \mathrm{~h}-\mathrm{HT}$ warrants additional comparative studies, with further extension of HT, in various models of HIE in the developing brain.

\section{REFERENCES}

1. van Bel F, Groenendaal F 2008 Long-term pharmacologic neuroprotection after birth asphyxia: where do we stand? Neonatology 94:203-210

2. Eicher DJ, Wagner CL, Katikaneni LP, Hulsey TC, Bass WT, Kaufman DA, Horgan MJ, Languani S, Bhatia JJ, Givelichian LM, Sankaran K, Yager JY 2005 Moderate hypothermia in neonatal encephalopathy: efficacy outcomes. Pediatr Neurol 32:11-17

3. Gluckman PD, Wyatt JS, Azzopardi D, Ballard R, Edwards AD, Ferriero DM, Polin RA, Robertson CM, Thoresen M, Whitelaw A, Gunn AJ 2005 Selective head cooling with mild systemic hypothermia after neonatal encephalopathy: multicentre randomised trial. Lancet 365:663-670

4. Shankaran S, Laptook AR, Ehrenkranz RA, Tyson JE, McDonald SA, Donovan EF, Fanaroff AA, Poole WK, Wright LL, Higgins RD, Finer NN, Carlo WA, Duara S, Oh W, Cotten CM, Stevenson DK, Stoll BJ, Lemons JA, Guillet R, Jobe AH 2005 Whole-body hypothermia for neonates with hypoxic-ischemic encephalopathy. N Engl J Med 353:1574-1584 
5. Azzopardi DV, Strohm B, Edwards AD, Dyet L, Halliday HL, Juszczak E, Kapellou O, Levene M, Marlow N, Porter E, Thoresen M, Whitelaw A, Brocklehurst P 2009 Moderate hypothermia to treat perinatal asphyxial encephalopathy. N Engl J Med 361:1349-1358

6. Nedelcu J, Klein MA, Aguzzi A, Martin E 2000 Resuscitative hypothermia protects the neonatal rat brain from hypoxic-ischemic injury. Brain Pathol 10:61-71

7. Haaland K, Løberg EM, Steen PA, Thoresen M 1997 Posthypoxic hypothermia in newborn piglets. Pediatr Res 41:505-512

8. Perlman JM 2006 Summary proceedings from the neurology group on hypoxicischemic encephalopathy. Pediatrics 117:S28-S33

9. Iwata O, Thornton JS, Sellwood MW, Iwata S, Sakata Y, Noone MA, O'Brien FE, Bainbridge A, De Vita E, Raivich G, Peebles D, Scaravilli F, Cady EB, Ordidge R, Wyatt JS, Robertson NJ 2005 Depth of delayed cooling alters neuroprotection pattern after hypoxia-ischemia. Ann Neurol 58:75-87

10. Trescher WH, Ishiwa S, Johnston MV 1997 Brief post-hypoxic-ischemic hypothermia markedly delays neonatal brain injury. Brain Dev 19:326-338

11. Taylor DL, Mehmet H, Cady EB, Edwards AD 2002 Improved neuroprotection with hypothermia delayed by 6 hours following cerebral hypoxia-ischemia in the 14-dayold rat. Pediatr Res 51:13-19

12. Rice JE 3rd, Vannucci RC, Brierley JB 1981 The influence of immaturity on hypoxic-ischemic brain damage in the rat. Ann Neurol 9:131-141

13. Thoresen M, Bagenholm R, Loberg EM, Apricena F, Kjellmer I 1996 Posthypoxic cooling of neonatal rats provides protection against brain injury. Arch Dis Child Fetal Neonatal Ed 74:F3-F9

14. Bona E, Hagberg H, Loberg EM, Bagenholm R, Thoresen M 1998 Protective effects of moderate hypothermia after neonatal hypoxia-ischemia: short- and long-term outcome. Pediatr Res 43:738-745

15. Wagner BP, Nedelcu J, Martin E 2002 Delayed postischemic hypothermia improves long-term behavioral outcome after cerebral hypoxia-ischemia in neonatal rats. Pediatr Res 51:354-360

16. Tomimatsu T, Fukuda H, Endoh M, Mu J, Kanagawa T, Hosono T, Kanzaki T, Doi K, Kubo T, Murata Y 2003 Long-term neuroprotective effects of hypothermia on neonatal hypoxic-ischemic brain injury in rats, assessed by auditory brainstem response. Pediatr Res 53:57-61

17. Zhu C, Wang X, Cheng X, Qiu L, Xu F, Simbruner G, Blomgren K 2004 Post-ischemic hypothermia-induced tissue protection and diminished apoptosis after neonatal cerebral hypoxia-ischemia. Brain Res 996:67-75

18. Covey MV, Oorschot DE 2007 Effect of hypothermic post-treatment on hypoxicischemic striatal injury, and normal striatal development, in neonatal rats: a stereological study. Pediatr Res 62:646-651

19. Yager J, Towfighi J, Vannucci RC 1993 Influence of mild hypothermia on hypoxicischemic brain damage in the immature rat. Pediatr Res 34:525-529

20. Paxinos G, Watson C 1998 The Rat Brain in Sterotaxic Coordinates. Academic Press, San Diego, CA

21. Nedelcu J, Klein MA, Aguzzi A, Boesiger P, Martin E 1999 Biphasic edema after hypoxic-ischemic brain injury in neonatal rats reflects early neuronal and late glial damage. Pediatr Res 46:297-304

22. O'Brien FE, Iwata O, Thornton JS, De Vita E, Sellwood MW, Iwata S, Sakata YS, Charman S, Ordidge R, Cady EB, Wyatt JS, Robertson NJ 2006 Delayed whole- body cooling to 33 or 35 degrees $\mathrm{C}$ and the development of impaired energy generation consequential to transient cerebral hypoxia-ischemia in the newborn piglet. Pediatrics 117:1549-1559

23. Carroll M, Beek O 1992 Protection against hippocampal CA1 cell loss by postischemic hypothermia is dependent on delay of initiation and duration. Metab Brain Dis 7:45-50

24. Coimbra C, Wieloch T 1994 Moderate hypothermia mitigates neuronal damage in the rat brain when initiated several hours following transient cerebral ischemia. Acta Neuropathol 87:325-331

25. Vannucci RC, Christensen MA, Yager JY 1993 Nature, time-course, and extent of cerebral edema in perinatal hypoxic-ischemic brain damage. Pediatr Neurol 9:29-34

26. Nakajima W, Ishida A, Lange MS, Gabrielson KL, Wilson MA, Martin LK, Blue ME, Johnson MV 2000 Apoptosis has a prolonged role in the neurogenesis after hypoxic ischemia in the newborn rat. J Neurosci 20:7994-8004

27. Li Y, Powers C, Jiang N, Chopp M 1998 Intact, injured, necrotic and apoptotic cells after focal ischemia in the rat. J Neurol Sci 156:119-132

28. Northington FJ, Ferriero DM, Graham EM, Traystman RJ, Martin LJ 2001 Early neurodegeneration after hypoxia-ischemia in neonatal rat is necrosis while delayed neuronal death is apoptosis. Neurobiol Dis 8:207-219

29. Geddes R, Vannucci RC, Vannucci SJ 2001 Delayed cerebral atrophy following moderate hypoxia-ischemia in the immature rat. Dev Neurosci 23:180-185

30. Sirimanne ES, Blumberg RM, Bossano D, Gunning M, Edwards AD, Gluckman PD, Williams CE 1996 The effect of prolonged modification of cerebral temperature on outcome after hypoxic-ischemic brain injury in the infant rat. Pediatr Res 39:591597

31. Gunn AJ, Gunn TR, de Haan HH, Williams CE, Gluckman PD 1997 Dramatic neuronal rescue with prolonged selective head cooling after ischemia in fetal lambs. J Clin Invest 99:248-256

32. Amess PN, Penrice J, Cady EB, Lorek A, Wylezinska M, Cooper CE, D'Souza P, Tyszczuk L, Thoresen M, Edwards AD, Wyatt JS, Reynolds EO 1997 Mild hypothermia after severe transient hypoxia-ischemia reduces the delayed rise in cerebral lactate in the newborn piglet. Pediatr Res 41:803-808

33. Graham GD, Blamire AM, Howseman AM, Rothman DL, Fayad PB, Brass LM Petroff OA, Shulman RG, Prichard JW 1992 Proton magnetic resonance spectroscopy of cerebral lactate and other metabolites in stroke patients. Stroke 23:333-340

34. Harada K, Honmou O, Liu H, Bando M, Houkin K, Kocsis JD 2007 Magnetic resonance lactate and lipid signals in rat brain after middle cerebral artery occlusion model. Brain Res 1134:206-213

35. Woo CW, Kim KS, Kim ST, Lee BS 2010 Correlation between lactate and neuronal cell damage in the rat brain after focal ischemia: An in vivo $1 \mathrm{H}$ magnetic resonance spectroscopic (1H-MRS) study. Acta Radiol 51:344-350

36. Gasparovic C, Rosenberg GA, Wallace JA, Estrada EY, Roberts K, Pastuszyn A, Ahmed W, Graham GD 2001 Magnetic resonance lipid signals in rat brain after experimental stroke correlate with neutral lipid accumulation. Neurosci Lett 301:87-90

37. Wang Y, Cheung PT, Shen GX, Wu EX, Cao G, Bart I, Wong WH, Khong PL 2006 Hypoxic-ischemic brain injury in the neonatal rat model: relationship between lesion size at early MR imaging and irreversible infarction. AJNR Am J Neuroradiol 27:51-54 